\title{
Women, Midwives, and a Medical Model of Maternity Care in Switzerland
}

\author{
Sue Brailey, Ans Luyben, Edwin van Teijlingen, and Lucy Frith
}

\begin{abstract}
This article presents a case study on the organization of maternity health care in Switzerland. Switzerland has a costly health care system with high intervention rates within an obstetric-led maternity care model. Evidence has shown that midwifery care is associated with lower cost, higher satisfaction rates among women, and less intervention. However, in this model, midwives are both marginalized and underused.

The article focuses on the distribution of power and knowledge between midwives, women, and the medical profession. The varying power structures that shape the maternity care system in Switzerland are examined, using a case study approach that draws on Foucault's concepts of the gaze, surveillance, disciplinary power, and the docile body. This article critically analyzes the model of maternity care received by women in Switzerland and how it negatively impacts on both women's personal and midwives' professional autonomy while simultaneously driving up costs.

A better understanding of the underlying power structures operating within the maternity care system may facilitate the implementation of more midwifery-led care currently being endorsed by the Swiss Midwifery Association and some government agencies. This could result in reduced cost and lower intervention rates with reduced associated morbidity.
\end{abstract}

KEYWORDS: Switzerland; midwifery; private health care; power; knowledge

\section{INTRODUCTION}

Midwifery-led care is associated with lower cost (Kenny et al., 2015), lower intervention rates (Kenny et al., 2015; Sandall, Soltani, Gates, Shennan, \& Devane, 2016), and high levels of satisfaction among women (Sandall et al., 2016) and midwives (Newton, McLachlan, Willis, \& Forster, 2014). Switzerland has a costly health care system (Organisation for Economic Co-operation and Development [OECD], 2014) and high levels of obstetric intervention (Bundesamt für Statistik [BFS], 2014) combined with low levels of midwifery-led care (Künzi, Jäggi, \& Dutoit, 2013; Schweizerischer Hebammenverband [SHV], 2013). Currently, both the Swiss Midwifery Association (SHV, 2013) and some government agencies (Eidgenössisches Departement des Innern, 2016; Künzi et al., 2013) are calling for more midwifery-led care to reduce health care costs and to fully use midwives. This article examines the maternity care system in Switzerland and argues that power structures within the system between the medical profession, midwives, and women serve to inhibit change and maintain the current structure.

The article begins with a description of the context in which the maternity system operates to understand how power structures work within this system. The distribution of power is then discussed, focusing on the effect of power on systems of knowledge, power distribution within the maternity care system, and how women and midwives are affected by disparities in personal and professional power. The Swiss organization of maternity services provides an example of how fee-for-service and a private health care system effects models of care and people's behavior operating within them. It is hoped that a better understanding of the underlying power structures operating in such a system 
may help other countries with similar maternity care models to implement more cost-effective midwifery-led services as seen in, for example, the United Kingdom or The Netherlands.

\section{Setting the Scene}

Switzerland is a small federal state made up of 26 cantons. The federal system affords the individual cantons with a high level of autonomy. The standard of living and gross domestic product (GDP) are high (OECD, 2014). The country has four official languages: German, French, Italian, and Romansch. Swiss society is defined by its distinct cultural differences reflected in the differing linguistic regions. The population is approximately eight million (BFS, 2014).

The position of women in Swiss society remains, in many ways, contradictory. Swiss women first attained the right to vote on a federal level in 1971, with the last canton finally granting women suffrage in 1991 (Gilardi, 2015). Despite this late introduction of universal suffrage, they have made up for lost time and now have $25 \%$ of the seats in the national parliament, putting Switzerland in the top third of European countries for women's representation in parliament. Swiss women are as well educated as men (Dutu, 2014) and female participation in the labor force is $78.5 \%$, although the level of part-time working is high (OECD, 2013). The net wage gap sits at about $7 \%$ in favor of men (Dutu, 2014).

\section{The Swiss Health Care System}

Switzerland has a high standard of health care, compared with other OECD countries, an above-average number of doctors, nurses, and access to state-of-theart medical technology (OECD, 2014). Switzerland is in second place for world life expectancy rates (World Health Rankings, 2017). It has a fee-for-service private health care system, funded by personal health insurance and state subsidy. This form of finance for health care is associated with high costs (Webster, 2007), and Switzerland has currently the third most expensive health care system in the world (OECD, 2014). Expenditure on health care is in part influenced by the existence of cartels between insurers and primary care providers regarding fee tariffs which drive up costs and means that the consumer has little influence over the price of their health care (Daley \& Gubb, 2013).
Individuals pay for their own private health insurance regardless of income. People can access specialists without there being a gatekeeper, like the general practitioner model in the United Kingdom (Loudon, 2008) although some health insurance companies are introducing this type of model to counteract the increasing costs. Many doctors work alone in their own private practice.

The Swiss health system is fragmented because of its organization along federal boundaries and operates within a free market neoliberal ethos (Actermann \& Berset, 2006). Although the Swiss report a high degree of satisfaction with their health care (Interpharma, 2015), there is a growing public debate about its cost and failing improvement in health outcomes (Actermann \& Berset, 2006; Daley \& Gubb, 2013; Eidgenössisches Departement des Innern, 2016; Künzi et al., 2013).

\section{Maternity Care in Switzerland}

Under the health insurance law (KrankenpflegeLeistungsverordnung, 1995) women with basic insurance who are considered low-risk are entitled to antenatal care; intrapartum care in a hospital, birthing center, or home setting; and postnatal care in hospital and at home. Both registered self-employed midwives and doctors can access payment by invoicing the woman's health insurance. Midwives and doctors employed by a hospital receive a wage, and the hospitals receive the payments from the health insurance company along with a state subsidy. Women can choose their caregiver and place of birth. Self-employed midwives offer a case loading model of midwifery care and birth at home, at a birthing center, and in hospital.

However, a minority of women access midwifery care and most women choose care from a private obstetrician. Women often have an exclusive relationship with their gynecologist who they may have been seeing regularly since a young age for contraception and gynecological screening. Switzerland has adopted a medical model of pregnancy and childbirth as described by van Teijlingen (2005), and this is illustrated by the medical dominance of maternity services as well as medical control over and monitoring of pregnant women and women in childbirth (MacKenzie-Bryers \& van Teijlingen, 2010).

Midwives work predominantly on the labor ward in hospital, where they attend laboring women, although doctors are present for the actual birth. Community midwifery is provided by self-employed midwives. The current out of hospital birth rate remains low at around 
$1 \%-2 \%$ (SHV, 2013). There is very little regulation of midwifery practice and no formal regulatory body exists. Indemnity insurance for private practice is cheap and readily available, reflecting the low rates of litigation in Switzerland.

Maternity statistics in Switzerland are incomplete and are collected by various agencies that do not communicate well with each other. The result is the information available is patchy but reflects a highly medicalized maternity care system (Luyben, Burkhardt, et al., 2013; Qualitäts Medizin Schweiz, 2015). Intervention rates are high, one in three women has a cesarean section (33.4\%), and the epidural rate is $50 \%-60 \%$ (BFS, 2014). Private hospitals have considerably higher rates of cesarean section despite serving a predominantly low-risk population (Qualitäts Medizin Schweiz, 2015; Walser, 2015). Women's voices are almost absent from the available statistics with little qualitative research available looking at women's experience of maternity care (Luyben, Burkhardt, et al., 2013).

Midwifery education is delivered to a high standard. Switzerland is a signatory to the Bologna Convention (The Official Bologna Website, 1999), which established a system of comparable degrees across the European Higher Education Area and is delivered in accordance with European Union directives. Postgraduate midwifery study is not well established, and, although growing, few Swiss midwives hold postgraduate or doctoral-level degrees (Luyben, Wijnen, Oblasser, Perrenoud, \& Gross, 2013). The lack of midwives with a postgraduate degree serves to undermine the status of the profession.

Having outlined the context of Swiss maternity care, the following section discusses the influence of a fee-for-service system and the effects that the exercise of power by society, institutions, and individuals has on the maternity care that Swiss women receive. It was therefore decided to use Foucault's (1980) theories around power and authority to underpin this case study.

\section{Power and Knowledge: Theoretical Underpinnings}

Foucault (1980) regards power and knowledge as being connected and coined the word "power/knowledge." Hence, society confers power on those that it believes have knowledge and that therefore knowledge confers power (Fahy, 2008). For Foucault (1980) convincing the public to accept a discipline's knowledge claim increases the power of that discipline. Doctors are traditionally held in high esteem in Switzerland and their knowledge is seldom questioned; thus, they wield a high degree of power in Swiss society. In addition to this, the medical profession is male dominated and gender-based power discrepancies result in a patriarchal maternity care system. The medical profession's knowledge is seen as being authoritative (Jordan, 1997); authoritative knowledge is defined as being the dominant knowledge system that carries more weight than others. In any domain, more than one knowledge system exists. However, often one system emerges as being dominant (authoritative) either because it suits the purposes better (efficacy) or because it is associated with a stronger power base (structural superiority). In the case of Switzerland, the authors argue both roles are fulfilled for medical knowledge. The presence of a private health care system run for profit is considered a strong driver for economic growth and needs doctors with a strong power base. The system of financing the Swiss health care system is recognized as being prone to cartel formation (Biller-Andorno \& Zeltner, 2015), and Swiss doctors often have high positions in health insurance companies, suggesting a conflict of interest. The establishment of authoritative knowledge is an on-going process that reflects power structures in society; ultimately all participants come to see the current status quo as being natural and "just the way things are." This has occurred in Switzerland and the dominance of the medical model in the maternity care system is rarely called into question.

Swiss women appear to display a high level of external locus of health control. Health locus of control refers to the degree to which individuals attribute their own health status to their own actions or external influence. An external locus of control is associated with a strong belief in the influence of powerful others. Doctors are often perceived as powerful others, whereas midwives are viewed in an assistant role to doctors rather than an autonomous practitioner. This is reflected in a qualitative study on women's experience of maternity care in Switzerland (Luyben, Burkhardt, et al., 2013) where women talked about the role of the doctor and the midwife in maternity care provision:

Ok the doctor for example, I trust him because he is the specialist, he knows, he has experience with pregnancy. . . . The midwife, is an advisor, a companion, more in the sense of a friend where I ask questions to do with the pregnancy that will maybe make things easier, or she can support me with a problem. (Sarah, after having her second child; Luyben, Burkhardt, et al., 2013) 
A recent study examining the views of women and midwives in relation to the establishment of a midwifery-led unit in Switzerland (Maillefer, de Labrusse, Cardia-Vonèche, Hohlfeld, \& Stoll, 2015) also illustrates women's dependence on doctors and mistrust of midwives' competence. Women's reluctance to acknowledge midwives as lead professionals and preferring to stay with their gynecologist was recognized by the researchers as being a potential barrier to setting up a midwifery-led unit.

In common with many other developed countries, the maternity care in Switzerland is dominated by a risk adverse medical model of care. The concept of obstetric hegemony can be used to understand how this has come about. Hegemony is understood as describing the social or cultural predominance of one group within a society. Obstetric hegemony operates via ideological leadership by a medical profession, privileged through both gender and class (Campo, 2010). This results in the medical model of care becoming normal and an accepted popular worldview. A fundamental underpinning of this is the framing of childbirth as being risky, dangerous and in need of close medical supervision. Reiger and Dempsey (2006) discuss how a "culture of fear" has come to define how childbirth is viewed and that a culture of anxiety and reliance on technology shapes how maternity care is delivered. This has been internalized by many women who then seek "safety" within the confines of a medical model of care. This hegemonic worldview leads to most women choosing obstetric-led care with its focus on technology rather than midwifery-led care.

\section{THE DISTRIBUTION OF POWER WITHIN THE MATERNITY CARE SYSTEM}

The maternity care received by Swiss women is shaped by the presence of strong allegiances between the health corporations, physicians, insurance firms, and health equipment suppliers, an arrangement described as the medical-industrial complex (MIC; Ehrenreich \& Ehrenreich, 1971). These allegiances, with their dependence on high-tech health technologies, manifest themselves with a preoccupation with screening, and obstetric care based on a liberal use of health care technology (HT). Power is situated within the confines of the MIC, and both midwives and service users are unable to take part because of restrictions based on professional rules and regulations. An example of the power of the MIC can be seen in the defeat of attempts to break up the health insurance industry in a referendum proposing the establishment of a single national health care insurer (Daley \& Gubb, 2013). This was defeated following intense lobbying by the medical profession and the health insurers who argued that people would lose their freedom of choice if they were restricted to one health care insurer (Daley \& Gubb, 2013).

The antenatal care received by Swiss women appears to be shaped by the presence of the MIC. An example of this being the ultrasound machine representing a "buyable" form of technology (Chakraborty \& Harding, 2003). Private doctors are encouraged to buy ultrasound equipment, potentially resulting in the overuse of antenatal ultrasound (Webster, 2007).

Many women receive an ultrasound examination at every antenatal consultation (Braun, 2007; Luyben, Burkhardt, et al., 2013), while disregarding advice to keep ultrasound to a minimum in pregnancy because of concerns regarding its safety (U.S. Food and Drug Administration, 2014). Its use also shifts the focus away from health promotion and normality and onto screening and the medicalization of health care. This overuse of ultrasound can be considered an expression of Foucault's concept the gaze where power is exercised through surveillance (Fillingham, 1993), the use of health care technology affords the doctor high levels of power over women because he or she is able to diagnose conditions without the woman experiencing any symptoms while at the same time marginalizing midwives who do not have access to the technology that many women now seek. Many doctors advertise their practice stating that they have a 3D scanner, and women are encouraged to see this as being an opportunity to see the baby rather than as a screening test (Braun, 2007). The importance of ultrasound to women was highlighted by Luyben (2008).

I chose a doctor who I felt could give me the best information and had a good ultrasound machine. (Lilian expecting her first child)

Of course, he also has to take the blood pressure and blood samples and so on. But I am mostly looking forward to, of course, if I can have an ultrasound and look at it. (Verena, after having her second child)

Proponents of private health care argue that the existence of such systems promotes choice. The reality, 
however, is that the low level of switching between health insurers and the fact that cartels do exist (Daley \& Gubb, 2013) means that the consumer ends up with very little influence over their maternity care.

The Swiss often see choice as meaning being able to choose their care provider and insurer (BillerAndorno \& Zeltner, 2015) not the content of care that they receive. In addition, strong cultural forces influence women to behave passively while facing an "expert" and support the status quo when they become pregnant. Although women do have a choice of caregiver in Switzerland, the concept of obstetric hegemony restricts many women from making their own, independent choices outside the cultural norm of obstetric-led care. The idea of choice when considering maternity care is a complex one and highlights the embodied social and cultural norms that restrain women's agency. Consequently, when confronted with the choice between the hegemonic norms of childbirth and midwifery-led care, most women intuitively choose to remain within the medical model rather than seek alternatives.

\section{Women's Power Within the Maternity Care System}

The importance of the establishment of a trusting relationship with their caregiver for women was highlighted in a study into antenatal care in three European countries, one of which being Switzerland (Luyben \& Fleming, 2005). An analysis of trust within health care settings (Gilson, 2003) revealed that when large discrepancies between the status of players exist, such as between women and gynecologists, trust often morphs into dependency. Many women in Switzerland have frequent contact with gynecologists. Their relationship with gynecologists often starts in adolescence. From a young age, women will see their gynecologist for contraception and yearly gynecological checks. This will continue throughout her reproductive life. For most women, the logical step when they become pregnant is to stay with their gynecologist for maternity care.

Cervical screening, alongside other gynecological screening, is often performed annually; despite a strong evidence base for three yearly examinations (Gasche, 2015). Apart from the obvious fiscal advantages to frequent screening the effect of this early introduction and continuous exposure to the discipline of gynecology can make regular gynecological examinations a cultural norm and foster a relationship based on dependency. This frequent screening for women is an example of the rise of surveillance medicine (Armstrong, 1995), healthy women are now continuously under the gaze (Foucault, 1980) of the medical profession. This gazing is the basis of the disciplinary power, as described by Foucault (1980), exerted over women by gynecologists. This disciplinary power is enforced by offering rewards for compliance and "punishments" for noncompliance for example, the offer of ensuring a woman's safety and a healthy baby if women comply with the care being offered and the threat of death and disability if women resist (Fahy, 2002). Moreover, labeling many women as being "high risk," ensures women's compliance through fear of something being wrong and the resulting dependence on the medical profession that this engenders. This engendering of fear also encourages learned helplessness, a process where women lose confidence to help themselves resulting in ever more dependency on health care professionals. Studies have shown that the more fearful women are during their pregnancy the more (learned) helplessness and reduced self-efficacy they exhibit (Lowe, 2009). Through the exercise of disciplinary power women remain docile; a concept used by Foucault to describe the effects of power on people and illustrated by research on women's experience of antenatal care in Australia (Fahy, 2002) which demonstrated through qualitative research, how women experience medical power within the maternity care system.

The issue of personal choice for women is bound up with the knowledge and information that women receive. Antenatal classes often consist of hospital run classes where doctors are often involved and the purpose is to inform women what services are on offer at the hospital. Private classes are available but are often based on physical preparation for childbirth. A culture of informed choice does not really exist in Switzerland, and women are often reluctant to come into conflict with their gynecologist for fear of invoking the disciplinary power that exists, particularly when they are in a vulnerable situation such as pregnancy (Luyben, 2008). This form of power often remains invisible until resistance is encountered and punishments occur. Doctors can threaten to withdraw care if women do not comply with their advice. The longlasting, often complex, relationship that women have with their gynecologists makes it difficult for women to resist forms of care that they may be unhappy with (Luyben, 2008).

When asked about discussing certain issues with their doctor (as an expert), women talked about feeling stupid and behaving very differently with their 
gynecologists during pregnancy compared to other stages in their lives (Luyben, Burkhardt, et al., 2013).

I would feel stupid [challenging the doctor] ... I don't know why, there are certain things I don't question ... normally I am a very grounded person and not weak, but there [during pregnancy] you are different, it is a different situation. (Paola, after having her first child)

In summary, the medicalization of maternity care in Switzerland during the last century seems to have led to a culture in which gynecologists in Switzerland hold disciplinary power over women. They maintain this power through their gaze and the use of surveillance medicine enabled by the liberal use of health technology, thereby building a culture of medicalized maternity care that then becomes a social norm. Women only encounter this power should they resist and are kept compliant by limiting the knowledge about the choices available to them through control of information, therefore reducing their own personal power (Fahy, 2002). Although women can in theory exercise choice regarding their maternity care, powerful social norms and influences often inhibit women from making choices outside of the status quo (Brailey, Jarrett, Luyben, \& Poat, 2015).

\section{Midwives' Power Within the Maternity Care System}

Within this medical model, the use of disciplinary power by the medical profession is also used to maintain the professional hierarchy between midwives and doctors. Midwives are subject to the gaze and disciplinary power (Foucault, 1980) of the medical profession, maintained by the close proximity of working relations and by a series of rewards and punishments. These sanctions include being shunned and ostracized by work colleagues for noncompliance, or being rewarded by being able to hand over responsibility to the medical profession, which leads to many midwives being content with their position in the hierarchy. Midwives consequently become docile within the power structures that exist (Sundin-Huard \& Fahy, 1999).

One of the main ways that midwives remain disempowered is by denying them access to pregnant women through the organization of antenatal care. Many women first meet a midwife while in labor. This prevents the formation of a partnership relationship between the midwife and woman (Mander, 2011), keeps midwives out the public sphere, and prevents them from being able to engage and empower women. Because of the organization being controlled and provision of maternity care being carried out predominantly by the medical profession, being "with woman" throughout the childbirth continuum is rarely possible for a midwife in Switzerland.

Recent moves to degree-level education for midwives (The Official Bologna Website, 1999) have resulted in midwifery education being more focused on educating critical, evidence-based, autonomous practitioners able to provide high-quality care in complex situations. The situation in practice however remains much the same and many midwives are unable to use all their skills (Luyben \& Robin, 2009; SHV, 2013). This dichotomy between the standard of midwifery education and the reality of midwives' disempowerment within the system represents how knowledge without liberation does not necessarily lead to more power or more autonomy (Brown, 2002). Foucault (1980) argues, knowledge is not necessarily predictive of the possession of power. Improving the education of Swiss midwives was not enough; they also need to challenge the organization of maternity care. Hence, the Swiss midwives' organization's campaign for midwife-led care (SHV, 2013) and steps to introduce an alongside midwifery-led unit (Maillefer et al., 2015). This has been met with considerable hostility from the medical profession, where the battle is not just for power and professional turf but also for livelihoods (Blick, 2013; Nowotny, 2013).

Improvements in midwifery education have led to some midwives in practice feeling undermined by the midwives with degree-level qualifications and increased bullying situations in the workplace (Gillen, Brailey, \& Luyben, 2012; Gillen, Sinclair, Kernohan, Begley, \& Luyben, 2017). This represents horizontal violence where disempowered groups resort to enforcing the disciplinary power that they themselves are subjected to rather than addressing those exercising the power.

One area of midwifery practice that is relatively free from the gaze and the use of disciplinary power are self-employed midwives. By removing themselves from institutions, they remain "under the radar" and practice according to their own midwifery framework. This can be liberating for the midwives who choose to work in this fashion and provides some women with the opportunity of receiving continuity of midwifery care but it is poorly regulated which can impact on public safety and serves to reinforce the view that the medical profession is the sole provider of safe care. In addition, there have been long-standing negotiations between the health insurance providers and the Swiss 
Midwifery Association regarding payment. Despite recent increases in payment for postnatal care provision, self-employed midwives continue to receive low levels of payment for their services which alongside the additional responsibility and self-employed status acts as a deterrent for many midwives to work in this fashion.

\section{THE WAY FORWARD}

In response to the high health care costs in Switzerland and underuse of midwives, there is increasing discussion around the implementation of more midwiferyled care. This has been supported by government reports keen to reduce costs and advocating for the more effective use of health care professionals (Eidgenössisches Departement des Innern, 2016; Künzi et al., 2013). In addition, the SHV has seized this debate as an opportunity to promote the midwifery profession (SHV, 2013).

This has resulted in a backlash from the medical profession (Blick, 2013; Nowotny, 2013) who have reasserted their claim on their monopoly of knowledge and expertise in maternity care. However, despite this backlash, some improvements are being made. These can be seen in the expansion of midwife-run free-standing birth centers and the increase in postnatal care being provided by self-employed midwives as a response to cost-saving early discharge measures from hospitals.

This current debate on the role of midwives could provide an opportunity for Swiss midwives to implement a system of professional supervision and regulation that could enable them to play a more active role in the provision of maternity care in Switzerland. Swiss maternity services could save money while introducing womancentered midwifery care (Künzi et al., 2013) as currently promoted by the Swiss Government Agenda 2020 (Eidgenössisches Departement des Innern, 2016) and the SHV's campaign for midwifery-led care (SHV, 2013).

\section{CONCLUSION}

Within the Swiss maternity system, there is a medical industrial complex that shapes the maternity care that women in Switzerland receive. A free-market private health care system with its neoliberal ideology results in little fiscal incentive to fully use the competencies of all professional groups and a strong medical model, with a vested financial and professional interest to maintain the status quo, ensures that midwives remain marginalized.
Swiss maternity care is dominated by the medical model and Swiss women often have a uniquely dependent relationship with their gynecologist which then inhibits them from seeking alternatives. A midwifery model of maternity care does exist and is practiced by self-employed midwives, but this type of care continues to remain on the fringes of maternity care provision.

Along with other pan-European developments, Swiss midwives have made great progress within the last decade particularly regarding increasing the educational level of practitioners. However, in practice, in most cases, they work under the direct auspices of the medical profession and experience little autonomy.

If Switzerland wishes to reduce its health costs and produce better outcomes for low-risk women, it needs to more fully use midwives. To do this, power structures within the current maternity care system will need to be challenged and new dynamics of care and interprofessional working adopted.

The Swiss organization of maternity services provides an example of how fee-for-service and a private health care system effects models of care and people's behavior operating within them. A better understanding of the underlying power structures operating in such a system may also help other countries with similar maternity care models reduce intervention rates and implement more cost-effective women-centered services.

\section{REFERENCES}

Actermann, W., \& Berset, C. (2006). Gesundheitspolitiken in der Schweiz-Potential für eine Nationale Gesundheitspolitik Band 1, Analyse und Perspektiven [Health care politics in Switzerland: Potential for a national health politic, edition 1, analysis and perspectives]. Bern, Switzerland: Bundesamt für Gesundheit.

Armstrong, D. (1995). The rise of surveillance medicine. Sociology of Health and Illness, 17(3), 97-114.

Biller-Andorno, N., \& Zeltner, T. (2015). Individual responsibility and community solidarity-the Swiss health care system. The New England Journal of Medicine, 373, 2193-2197.

Blick, C. H. (2013 , May 16). Hebammen gegen Gynäkologen: Kampf im Gebärsaal per Petition lanciert [Midwives against gynaecologists: Fight in the labour ward launched by petition] Blick.CH. http://www.blick .ch/news/schweiz/hebammen-gegen-gynaekologenkampf-im-gebaersaal-per-petition-lanciert-id2304952 .html. 
Brailey, S., Jarrett, P., Luyben, A., \& Poat, A. (2015). Swimming against the tide: Women's experience of choosing a homebirth in Switzerland. British Journal of Midwifery, 23(11).

Braun, G. (2007, February). Dickes Geschäft mit dem Ultraschall [Rich pickings with ultrasound]. Gesundheitstip, 27. Retrieved from https://www.ktipp.ch/artikel/d/ dickes-geschaeft-mit-dem-ultraschall/

Brown, A. (2002). Foucauldian perspectives on midwifery practices and education. Journal of Advanced Nursing, 6(1), 34-42.

Bundesamt für Statistik. (2014). Geburten und Fruchtbarkeit, Lebendgeburten 2012 [Births fertility and live births 2012]. Retrieved from http://www.bfs.admin.ch/bfs/ portal/de/index/themen/01/06/blank/key/02.html

Campo, M. (2010). Trust, power and agency in childbirth: Women's relationships with obstetricians. Outskirts Online Journal, 22, 3. Retrieved from http://www .outskirts.arts.uwa.edu.au/volumes/volume-22/campo

Chakraborty, S., \& Harding, A. (2003). Conducting a private health sector assessment, In A. Harding \& A. Preker (Eds.), Private participation in health services (pp. 75-157). Washington, DC: World Bank.

Daley, C., \& Gubb, J. (2013). Healthcare systems: Switzerland. Retrieved from http://www.civitas.org.uk/nhs/download/switzerland.pdf

Dutu, R. (2014). Women's role in the Swiss economy (OECD Economics Department Working Papers No. 1144). Paris, France: Organisation for Economic Co-operation and Development.

Ehrenreich, B., \& Ehrenreich, J. (1971). The American health empire: Power, profits, and politics. New York, NY: Random House.

Eidgenössisches Departement des Innern. (2016). Health 2020. Bern, Switzerland.

Fahy, K. (2002). Reflecting on practice to theorise empowerment for women: Using Foucault's concepts. Australian Journal of Midwifery, 15(1), 5-13.

Fahy, K. (2008). Evidence-based midwifery and power/ knowledge. Women and Birth, 21(1), 1-2.

Fillingham, L. (1993). Foucault for beginners. Danbury, CT: Writers and Readers.

Foucault, M. (1980). Power/knowledge: Selected interviews \& other writings. New York, NY: Vintage Books.

Gasche, U. (2015, July 19). Eine Million unnötige Abstriche der Gebärmutter [A million unnecessary cervical smear tests]. Infosperber. Retrieved from http://www .infosperber.ch/Gesundheit/Frauenarzte-Eine-Millionunnotige-Abstriche-der-Gebarmutter

Gilardi, F. (2015). The temporary importance of role models for women's political representation. American Journal of Political Science, 59(4), 957-970.
Gillen, P., Brailey, S., \& Luyben, A. (2012, May). Student midwives experiences of bullying during training. Poster session presented at the Swiss Midwifery Association Congress, Schwyz, Switzerland.

Gillen, P., Sinclair, M., Kernohan, W., Begley, C., \& Luyben, A. (2017). Interventions for prevention of bullying in the workplace. Cochrane Database of Systematic Reviews, (1), CD009778. Retrieved from http://onlinelibrary.wiley .com/doi/10.1002/14651858.CD009778.pub2/pdf

Gilson, L. (2003). Trust and the development of health care as a social institution. Social Science \& Medicine, 56(7), 1453-1468.

Interpharma. (2015). Swiss healthcare and pharmaceutical market. Basel, Switzerland: Author.

Jordan, B. (1997). Authoritative knowledge and its construction. In R. Davis-Floyd \& C. Sargent (Eds.), Childbirth and authoritative knowledge (pp. 55-79). Oakland, CA: University of California Press.

Kenny, C., Devane, D., Normand, C., Clarke, M., Howard, A., \& Begley, C. (2015). A cost-comparison of midwife-led compared with consultant-led maternity care in Ireland (the MidU study). Midwifery, 31(11), 1032-1038.

Krankenpflege-Leistungsverordnung. (1995). September 1995 über Leistungen in der obligatorischen Krankenpflegeversicherung Art $13 b$ [Nursing performance regulation of 29 September 1995 on services in the mandatory health insurance]. Retrieved from http://www.admin.ch/ch/d/ sr/c832_112_31.html

Künzi, K., Jäggi, J., \& Dutoit, L. (2013). Aktueller Stand der schweizerischen Diskussion über den Einbezug von hoch ausgebildeten nichtärztlichen Berufsleuten in der medizinischen Grundversorgung [Current status of the Swiss debate on the involvement of highly trained non-medical professional people in primary care: Update on the Working Document 27 Schlussbericht Obsan]. Neuchâtel, Switzerland: Schweizerisches Gesundheitsobservatorium.

Loudon, I. (2008). The principle of referral: The gatekeeping role of the GP. The British Journal of General Practice, 58(547), 128-130.

Lowe, N. K. (2009). Self-efficacy for labor and childbirth fears in nulliparous pregnant women. Journal of Psychosomatic Obstetrics and Gynaecology, 21(4), 219-224.

Luyben, A. (2008). Mothering the mother: A study of effective content of routine care during pregnancy from women's points of view in three European countries (Doctoral Dissertation). Glasgow, Scotland: Glasgow Caledonian University.

Luyben, A., Burkhardt, K., Conca, A., Gurtner-Zürcher, C., Hähnlein, K., Brailey, S., \& Forster Fink, R. (2013). MatHER-ch.ch: Maternal health experiences research during childbirth in Switzerland. Final report. Bern, Switzerland: Bern University of Applied Sciences. 
Luyben, A., \& Fleming, V. E. (2005). Women's needs from antenatal care in three European countries. Midwifery, 21(3), 212-223.

Luyben, A., \& Robin, O. (2009). Summary of the analysis of the cantonal laws in Switzerland in order to match midwifery activities with competencies on a national and international level [Monograph]. Bern, Switzerland: Bern University of Applied Sciences/Haute école de santé Vaud.

Luyben, A., Wijnen, H. A., Oblasser, C., Perrenoud, P., \& Gross, M. (2013). The current state of midwifery and development of midwifery research in four European countries. Midwifery, 29(5), 417-424.

MacKenzie-Bryers, H, \& van Teijlingen, E. (2010). Risk, theory, social and medical models: A critical analysis of the concept of risk in maternity care. Midwifery, 26(5), 488-496.

Maillefer, F., de Labrusse, C., Cardia-Vonèche, L., Hohlfeld, P., \& Stoll, B. (2015). Women and healthcare providers' perceptions of a midwife-led unit in a Swiss university hospital: A qualitative study. BMC Pregnancy and Childbirth, 15, 56.

Mander, R. (2011). The partnership model. In R. Bryar \& M. Sinclair (Eds.), Theory for midwifery practice (pp. 215-240). Hampshire, United Kingdom: Palgrave Macmillan.

Newton, M. S., McLachlan, H. L., Willis, K. F., \& Forster, D. A. (2014). Comparing satisfaction and burnout between caseload and standard care midwives: Findings from two cross-sectional surveys conducted in Victoria, Australia. BMC Pregnancy and Childbirth, 14(1), 426.

Nowotny, S. (2013). Hebammen wollen ans Ruder [Midwives want to take the helm]. Retrieved from http://www .nzz.ch/aktuell/startseite/hebammen-wollen-ansruder-1.18079908

Organisation for Economic Co-operation and Development. (2013). Labour force statistics. Paris, France: Author.

Organisation for Economic Co-operation and Development. (2014). Gross domestic product (GDP). Paris, France: Author.

Qualitäts Medizin Schweiz [Hospital comparison]. (2015). Retrieved from http://www.qualitaetsmedizin.ch/ bag-spitalvergleich-geburten/

Reiger, K., \& Dempsey, R. (2006). Performing birth in a culture of fear: An embodied crisis of late modernity. Health Sociology Review, 15(4), 364-373.

Sandall, J., Soltani, H., Gates, S., Shennan, A., \& Devane, D. (2016). Midwife-led continuity models versus other models of care for childbearing women. Cochrane Database of Systematic Reviews, (4), CD004667.

Schweizerischer Hebammenverband. (2013). Positionspapier zum Thema Hebammengeleitete geburtshilfliche Modelle (HgM) [Position paper on midwifery-led model of maternity care]. Retrieved from http://www.hebamme.ch/x_data/ allgdnld/Positionspapier\%20HgM_ZV_5_9_20131.pdf

Sundin-Huard, D., \& Fahy, K. (1999). Moral distress, advocacy and burnout: Theorizing the relationships. International Journal of Nursing Practice, 5(1), 8-13.

The Official Bologna Website. (1999). Retrieved from http:// www.ond.vlaanderen.be/hogeronderwijs/bologna/

U.S. Food and Drug Administration. (2014). FDA cautions ultrasound "keepsake" images. January-February 2014. Retrieved from http://www.fda.gov/fdac/features/ 2004/104_images.html

van Teijlingen, E. (2005). A critical analysis of the medical model as used in the study of pregnancy and childbirth. Sociological Research Online, 10(2), 1-15.

Walser, B. (2015, July). Private machen mehr Kaiserschnitte [Private carers carry out more caesarean sections] Berner Zeitung. Retrieved from http://mobile2 .bernerzeitung.ch/articles/25730309

Webster, A. (2007). Health, technology, and society: A sociological critique. Hampshire, United Kingdom: Palgrave Macmillan.

World Health Rankings. (2017). Switzerland: Life expectancy. Retrieved from http://www.worldlifeexpectancy.com/ switzerland-life-expectancy

Correspondence regarding this article should be directed to Sue Brailey, RM, MSc, Middlesex University, 21 Sprules Rd, London, SE4 2NL, UK. E-mail: S.Brailey@mdx.ac.uk

Sue Brailey, RM, MSc, School of Health and Education, Middlesex University, The Burroughs, London, United Kingdom.

Ans Luyben, RM, PhD, Spital STSAG, Thun, Switzerland; Institute of Psychology, Health and Society, University of Liverpool, Liverpool, United Kingdom; Faculty of Health and Social Sciences Care, Bournemouth University, Bournemouth, Dorset, United Kingdom.

Edwin van Teijlingen, PhD, Centre for Midwifery, Maternal \& Perinatal Health, Bournemouth University, Bournemouth, Dorset, United Kingdom.

Lucy Frith, PhD, Department of Health Services Research, University of Liverpool, Liverpool, United Kingdom. 